\title{
Nuclear 8-hydroxy-2'-deoxyguanosine as survival biomarker in patients with cutaneous melanoma
}

\author{
DANIELA MURTAS ${ }^{1}$, FRANCA PIRAS $^{1}$, LUIGI MINERBA ${ }^{2}$, JORGE UGALDE ${ }^{1,3}$, CARLO FLORIS $^{4}$, \\ CRISTINA MAXIA ${ }^{1}$, PAOLO DEMURTAS ${ }^{1}$, MARIA TERESA PERRA ${ }^{1}$ and PAOLA SIRIGU ${ }^{1,3}$ \\ ${ }^{1}$ Department of Cytomorphology, University of Cagliari, Italy Cittadella Universitaria, 09042 Monserrato (CA); \\ ${ }^{2}$ Department of Public Health, University of Cagliari, Via Porcell, 09124 Cagliari, Italy; \\ ${ }^{3}$ Department of Pathology, Cancer Institute, Solca, Ecuador Av. Del Paraíso y Agustín Landívar, \\ Cuenca, Ecuador; ${ }^{4}$ Oncologic Hospital ‘Businco', Cagliari, Via Jenner, 09121 Cagliari, Italy
}

Received August 4, 2009; Accepted October 5, 2009

DOI: 10.3892/or_00000640

\begin{abstract}
OHdG) is one of the main mutagenic modifications induced in DNA by oxidative stress. Elevated levels of $8-\mathrm{OHdG}$ have been regarded as an independent prognostic factor in different types of cancer. Various enzymes, such as human 8-oxoguanine DNA-glycosylase 1 (hOGG1) and glucose-6-phosphate dehydrogenase (G6PD), act as protection against oxidative stress. The low activity of such enzymes has been consistently associated with increased risk of progression in several tumor types. The aim of this study was to investigate whether 8OHdG, hOGG1 and G6PD expression in tumor tissues might be a predictor of survival in melanoma patients. The expression of 8-OHdG, hOGG1 and G6PD was immunohistochemically investigated in primary cutaneous melanoma and the effect on survival was analyzed. Furthermore, the immunostaining for p53 and survivin was evaluated and the relationship among 8-OHdG, hOGG1, G6PD, p53 and survivin expression was analyzed. Kaplan-Meier analysis demonstrated that patients with low expression of nuclear 8-OHdG had significantly longer survival time compared with those with a high expression $(\mathrm{P}=0.032)$, whereas cancerspecific survival of patients was not associated with hOGG1 or G6PD expression. These results suggest an involvement of oxidative DNA damage in the process of melanoma pathogenesis and demonstrate that $8-\mathrm{OHdG}$ expression in nuclei of tumor cells could be useful as an early independent prognostic marker in patients with primary cutaneous melanoma.
\end{abstract}

Correspondence to: Professor Paola Sirigu, Department of Cytomorphology, University of Cagliari, Cittadella Universitaria, 09042 Monserrato (CA), Italy

E-mail: psirigu@unica.it

Key words: melanoma, oxidative DNA damage, 8-hydroxy-2'deoxyguanosine, survival biomarkers

\section{Introduction}

Ultraviolet radiation-induced oxidative DNA damage is believed to be implicated in the pathogenesis of many tumors, including cutaneous melanoma (1-4). 8-hydroxy-2'-deoxyguanosine $(8-\mathrm{OHdG})$ is one of the main mutagenic oxidative modifications induced in DNA and is considered a reliable marker of DNA damage induced by oxidative stress $(5,6)$. The presence of $8-\mathrm{OHdG}$ in DNA has a pro-mutagenic potential by mispairing with $\mathrm{A}$ residues, leading to an increased frequency of spontaneous $\mathrm{G}$ : $\mathrm{C}$ to $\mathrm{T}$ :A transversion, mutagenesis, or cell death unless correctly repaired before DNA replication (7). This mutation is generally observed in mutated proto-oncogenes and tumor suppressor genes (8). Various enzymes, such as human 8-oxoguanine DNA-glycosylase 1 (hOGG1) and glucose-6-phosphate dehydrogenase (G6PD), act as protection against oxidative stress. hOGG1 is involved in the repair and prevention of $8-\mathrm{OHdG}$-derived mutations, by catalyzing the excision and removal of $8-\mathrm{OHdG}$ adducts (9) and its expression may be up-regulated by the exposure to oxidative DNA damage (10). G6PD is indispensable to reductive metabolism and maintenance of cellular redox homeostasis, being involved in the generation of NADPH required for the protection against oxidative damage (11). 8-OHdG residues on DNA, excised by enzymatic repair systems, appear in the blood and subsequently excreted in the urine (12). 8-OHdG level in blood and/or urine has been measured as a marker of oxidative DNA damage (13). The finding of the $8-\mathrm{OHdG}$ expression in tumor tissue directly shows the degree of oxidative damage on DNA $(14,15)$. It is known that accumulation of impaired $8-\mathrm{OHdG}$ could lead to increased genomic instability that in turn could lead to a more malignant phenotypic behaviour of tumors (9). On the other hand, the low activity of enzymes, such as hOGG1 and G6PD, has been consistently associated with increased risk of progression in several tumor types $(16,17)$.

Previous studies suggested an involvement of oxidative stress in the ultraviolet (UV) activation of the tumor suppressor gene $p 53$, whose product plays an important role in the regulation of cellular response to DNA damage. In many cells, exposure to UV light leads to a dramatic increase in the cellular 
levels of the tumor suppressor protein p53, followed by a biological response of either growth arrest or programmed cell death (18). Up-regulation of wild-type p53 results in a transient G1 arrest, allowing cells to repair the DNA damage before resuming the cell cycle. Wild-type p53 has also been suggested to repress transcription of the survivin gene (19). Survivin is a member of the inhibitor of apoptosis protein (IAP) family (20), undetectable in most differentiated normal tissues, but strongly expressed in embryonic and fetal organs (21). Survivin has been implicated in cell division, prevention of apoptosis, cellular stress response and checkpoint mechanisms of genomic integrity (22). It is overexpressed in many human malignancies and such overexpression is associated with poor prognosis $(23,24)$. Although survivin and p53 are both critical modulators of the opposing cellular processes of proliferation and apoptosis, there is currently no evidence of interaction between mechanisms regulating the expression of each.

Despite the numerous clinicopathological factors with prognostic value currently available, none of them can accurately predict the clinical outcome of melanoma patients. Since the malignant phenotype of tumors is sustained by the complex molecular derangement of tumor cells, the identification of novel molecular markers, sought mainly in the primary tumor and suggestive of cancer aggressiveness, could provide clinicians with novel and more effective prognostic tools (25).

In this study, we immunohistochemically investigated the expression of 8-OHdG, hOGG1, G6PD, p53 and survivin in primary cutaneous melanoma and the relationship among these factors was analyzed. Our aim was to evaluate whether 8-OHdG, hOGG1 and G6PD expression in tumor tissues might be a predictor of survival in melanoma patients. The correlation between 8-OHdG, hOGG1 and G6PD expression and clinicopathological factors of patients was also examined.

\section{Materials and methods}

Samples. Archival tissue blocks of sporadic primary cutaneous melanoma from 81 patients, who underwent observation at the Oncologic Hospital 'Businco', Cagliari, Italy and at the Department of Pathology, Cancer Center of Solca, Cuenca, Ecuador, between November 1995 and April 2008, were selected for further study according to the following criteria: melanoma with vertical growth phase and complete clinical data, including the follow-up, until April 2008. Lymph node status and the presence of metastases were verified by a clinical and pathological examination. This study included a total of 81 Stage I, II, III and IV melanoma patients, whose clinicopathological features are shown in Table I. The patients included 35 men and 46 women, ranging in age from 4 to 100 years (median, 68 years). The anatomic location of the primary tumor included 17 tumors located in the head and neck, 15 in the trunk, 12 in the upper extremities and 37 in the lower extremities. According to Clark's classification (26), 3 tumors were level II, 15 level III, 24 level IV and 39 level V. According to the American Joint Committee on Cancer (AJCC) staging system (27), 49 tumors were stage I-II and 32 were stage III-IV. Regarding tumor thickness, 18 tumors were classified T1-T2 and 63 were T3-T4.
Table I. Clinicopathological characteristics of 81 cutaneous melanoma patients.

\begin{tabular}{lc}
\hline Characteristics & All patients $(\mathrm{n}=81)$ \\
\hline Age at diagnosis $(\%)$ & $41(50.6)$ \\
$\leq 68^{\mathrm{a}}$ & $40(49.4)$ \\
$>68$ & \\
Gender $(\%)$ & $35(43.2)$ \\
Men & $46(56.8)$ \\
Women & \\
Tumor thickness $(\%)$ & $18(22.2)$ \\
T1-T2 & $63(77.8)$ \\
T3-T4 & \\
Clark level (\%) & $18(22.2)$ \\
II-III & $63(77.8)$ \\
IV-V & \\
Stage $(\%)$ & $49(60.5)$ \\
I-II & $32(39.5)$ \\
III-IV & \\
Anatomic location $(\%)$ & $17(21.0)$ \\
Head and neck & $15(18.5)$ \\
Trunk & $12(14.8)$ \\
Upper extremities & $37(45.7)$ \\
Lower extremities & \\
\end{tabular}

${ }^{a}$ Median value.

Each tumor, after surgical resection, was fixed in formalin and completely embedded in multiple paraffin blocks. The sections taken from the block with the largest tumor thickness were evaluated. Tumoral areas were identified on haematoxylin and eosin-stained sections and on adjacent sections immunohistochemically stained for melanoma-associated antigens, including S-100 protein, melan A and HMB-45. An independent histopathological analysis was performed by two pathologists (C.F. and J.U.) on separate occasions. The study protocol was approved by the Research Ethics Committee at our institutions and informed consent was obtained from all the patients involved in the study.

Immunohistochemistry. Serial microtome sections, $5-\mu \mathrm{m}$ thick, were treated for the immunohistochemical demonstration of 8-OHdG, hOGG1, G6PD, p53, survivin and melanomaassociated antigens S100, melan A, and HMB45 by using the alkaline phosphatase-streptavidin method.

Antigen retrieval was performed by heating at $95^{\circ} \mathrm{C}$ for $40 \mathrm{~min}$ in $10 \mathrm{mM}$ citrate buffer solution ( $\mathrm{pH} \mathrm{6.0)}$, followed by gradual cooling for $20 \mathrm{~min}$, for the demonstration of $8-\mathrm{OHdG}$, hOGG1, p53, survivin and melan A and by immersion in $0.1 \%$ trypsin solution in PBS at $37^{\circ} \mathrm{C}$ for 5 or $10 \mathrm{~min}$ for G6PD or $\mathrm{S}-100$ protein and the HMB-45 antigen, respectively. For the demonstration of $8-\mathrm{OHdG}$, the sections were incubated in $10 \mathrm{mM}$ Tris- $\mathrm{HCl} \mathrm{pH} 7.5,1 \mathrm{mM}$ EDTA, $0.4 \mathrm{mM} \mathrm{NaCl}$, $100 \mu \mathrm{g} / \mathrm{ml} \mathrm{RNase}$ for $1 \mathrm{~h}$ at $37^{\circ} \mathrm{C}$. To denature DNA, slides were soaked in $4 \mathrm{~N} \mathrm{HCl}$ for $7 \mathrm{~min}$ and then neutralized by incubation in $50 \mathrm{mM}$ Tris-base for $5 \mathrm{~min}$ at room temperature. 
Non-specific binding was blocked with $10 \%$ normal goat or normal horse serum for $45 \mathrm{~min}$. Mouse monoclonal antibody to 8-OHdG (Trevigen, Gaithersburg, MD, USA, 1:300 dilution), to human p53 protein (clone DO-7, Dakopatts, Glostrup, Denmark, 1:50 dilution), to human melan A (clone A103, Dakopatts, 1:100 dilution), and to human HMB-45 (clone HMB-45, Dakopatts, 1:100 dilution), rabbit polyclonal antibodies to human OGG1 (Novus Biologicals, Littleton, CO, USA, 1:100 dilution), to human G6PD (Novus Biologicals, 1:100 dilution), to recombinant human survivin protein (Novus Biologicals, 1:2000 dilution), and to bovine S-100 protein (Dakopatts, 1:1000 dilution) were used as primary antisera. Biotinylated anti-mouse and anti-rabbit immunoglobulins $\mathrm{G}$ (Vector Laboratories, Burlingame, CA, USA, 1:800 and 1:200 dilution, respectively) were used as secondary antisera. The sections were further incubated in alkaline phosphatasestreptavidin (Vector Laboratories, 1:1000 dilution) for $30 \mathrm{~min}$ at room temperature, reacted with Fast Red Substrate System (Dakopatts), and counterstained with Mayer's haematoxylin.

Sections of melanoma, strongly expressing 8-OHdG and p53, were used as positive controls for 8 -OHdG and p53, respectively, whereas sections of rat testis were used as positive controls for survivin, and sections of tonsil and parotid gland as positive controls for hOGG1 and G6PD staining, respectively. Negative controls were established by replacing the primary antibodies with normal serum.

Evaluation of immunoreactivity. The entire tumor of each case was microscopically examined through x200 magnification fields with a 144-intersection point square reticulum $\left(0.78 \mathrm{~mm}^{2}\right)$ inserted in the eyepiece, to identify and count $8-\mathrm{OHdG}$-positive cells in the nucleus, in the cytoplasm, or both, of the whole tumor and the average of these counts was considered. In the same way, adjacent sections from the same samples were evaluated for nuclear or cytoplasmic hOGG1, cytoplasmic G6PD, nuclear p53 and nuclear or cytoplasmic survivin immunoreactivity.

The results were stratified according to a staining score that took into account both percentage of positive cells and staining intensity. The samples were scored as positive for the expression of 8-OHdG, hOGG1, G6PD, p53 and survivin when $>10 \%$ of tumor cells showed a moderate/strong staining intensity; otherwise, they were scored as negative.

Statistical analysis. Data were computed with the Statistical Package for the Social Sciences (SPSS) 15.0 software. The association between 8-OHdG, hOGG1, G6PD, p53 and survivin expression and the correlation of $8-\mathrm{OHdG}$, hOGG1 and G6PD expression with the clinicopathological variables of Stage I, II, III, and IV melanoma patients was assessed by Fisher's exact test or Pearson's $\chi^{2}$ test. Overall survival of patients with Stage I and II melanoma was calculated from the date of histological diagnosis to the date the patients died of melanoma, or the last follow-up, until April 2008. Survival information was unavailable for one patient. Data on patients who died of other causes were censored at the time of death. Survival curves were obtained using the Kaplan-Meier method, comparisons were made using the log-rank test and were adjusted for specified prognostic factors. The $95 \%$ confidence intervals $(95 \% \mathrm{CI})$ for survival were calculated and reported.
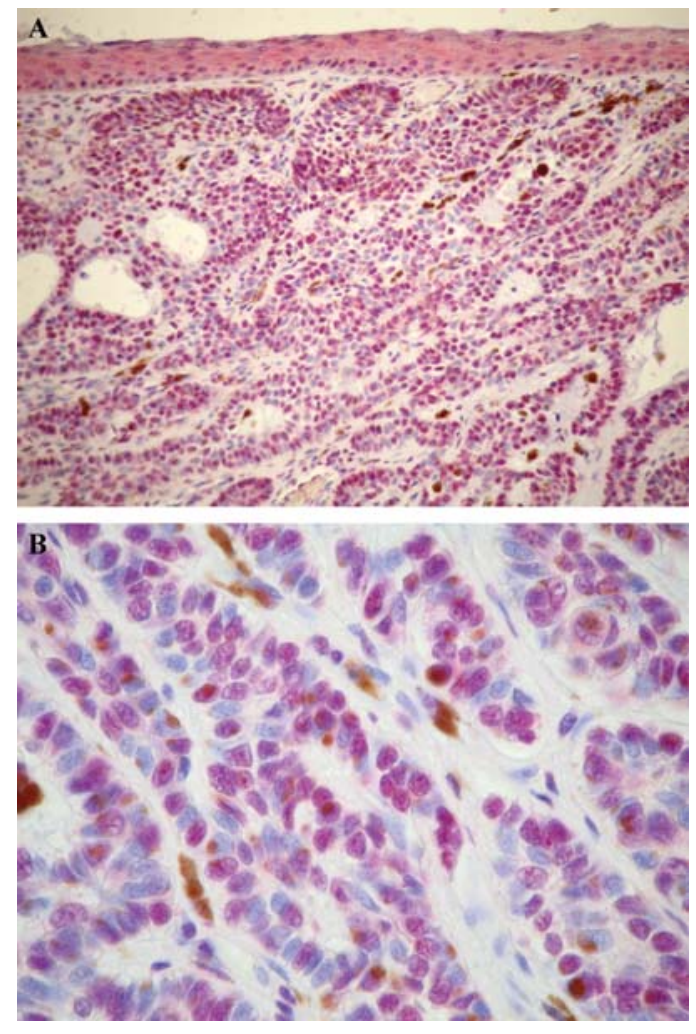

Figure 1. Immunohistochemical staining for 8-OHdG in melanoma. Moderate/ strong nuclear 8-OHdG immunoreactivity was observed throughout the whole tumoral area (A and B). Original magnification: x200 (A), x630 (B).

All tests used were two-sided. Differences were considered statistically significant at $\mathrm{P} \leq 0.05$.

\section{Results}

Immunohistochemistry. Immunoreactivity for $8-\mathrm{OHdG}$ was observed both in the nuclear and cytoplasmic compartment of tumor cells in $65 \%$ of cases, being more intense in the nucleus. 8-OHdG-positive tumor cells were spread throughout the tumoral area. Cytoplasmic immunoreaction was localized in a small amount of tumor cells with respect to nuclear staining (Fig. 1A and B).

p53 expression, restricted to the nuclei of tumor cells, was found in $64 \%$ of samples and, in most cases, the staining intensity was from moderate to strong. p53-positive cells were observable throughout the tumor and in the basal epidermal layers (Fig. 2A and B).

Survivin immunoreaction was detected both in nucleus and cytoplasm in $47 \%$ of cases, exclusively in nuclei in $19 \%$ of cases. Survivin-positive cells were distributed homogeneously throughout the tumor of some cases, while others showed heterogeneous staining pattern with positive and negative cells side by side. Staining intensity was different between nuclear and cytoplasmic compartment, being more intense in the nucleus. Mitotic figures were also intensely stained, being survivin localized to mitotic spindles and chromosomes. Epidermis surrounding the tumor showed survivin cytoplasmic staining in all layers but basal layers also showed nuclear staining with higher intensity than cytoplasm (Fig. 2C and D). 

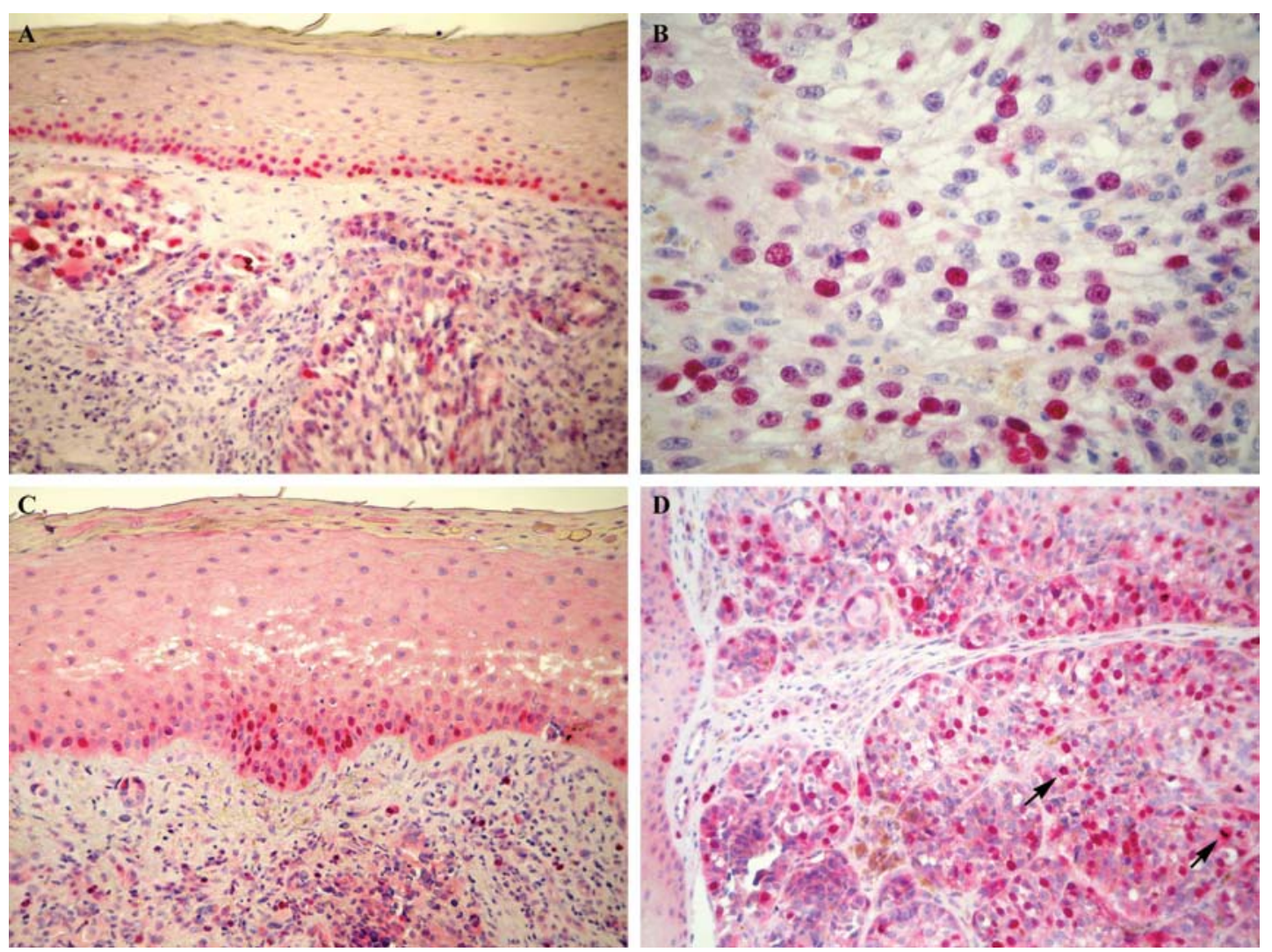

Figure 2. Immunohistochemical expression of p53 and survivin in melanoma. Strong nuclear immunoreactivity for p53 was detected in the basal epidermal layers (A) and throughout the whole tumor (B). Nuclear and cytoplasmic expression of survivin was detected in the epidermis (C) and throughout the tumoral area (D), being more intense in the nucleus. Some positive mitotic figures were also observable (D, arrows). Original magnification: x200 (A, C and D), x400 (B).
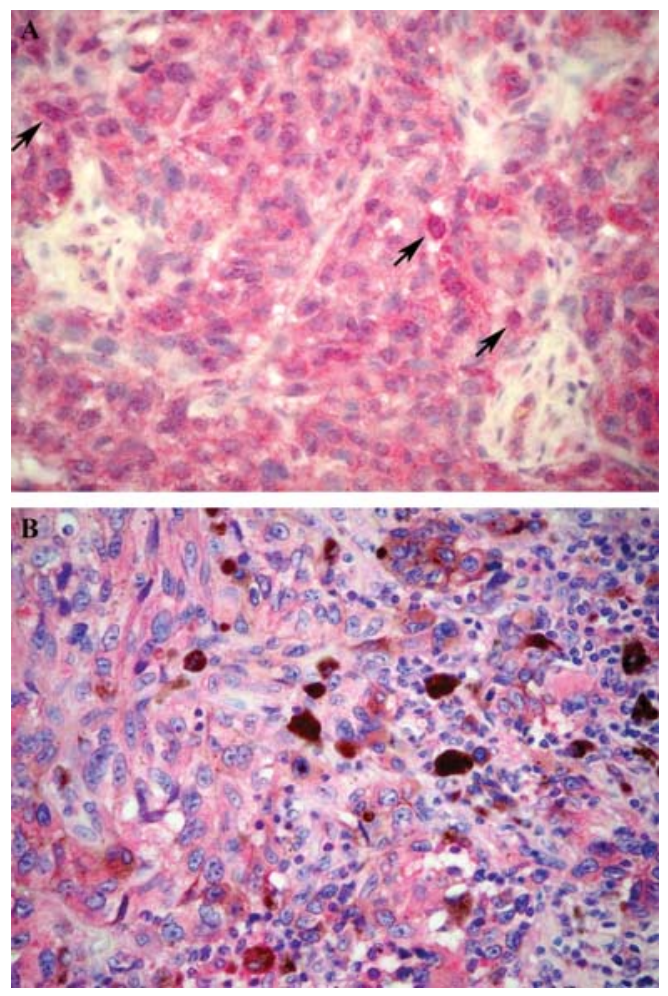

Figure 3. Immunohistochemical detection of hOGG1 and G6PD in melanoma hOGG1 expression was found in the cytoplasm of tumor cells and in scattered nuclei (arrows) (A). Tumor cells showed an intense cytoplasmic G6PD immunoreactivity (B). Original magnification: x400 (A and B).
In most samples, the distribution of p53 and survivinpositive cells was similar to that of 8-OHdG-stained cells.

Regarding protection factors against oxidative stress, we obtained the following results: $24 \%$ of samples showed an intense immunoreactivity for hOGG1 in the cytoplasm of tumor cells and in scattered nuclei. hOGG1-positive tumor cells were distributed throughout all the tumor and showed either a homogeneous or a fine granular staining pattern both in the nucleus and the cytoplasm (Fig. 3A). A positive staining for hOGG1 in tumor cells was more frequent in cases positive for 8 -OHdG.

G6PD immunoreaction, restricted to the cytoplasm of tumor cells, was found in $24 \%$ of cases, with positive cells distributed throughout all the tumor. Some cases demonstrated homogeneous staining intensity in the cytoplasmic compartment of tumor cells, while in others a heterogeneous staining pattern was found with some cells showing a stronger intensity than others (Fig. 3B).

Statistical analysis. Positive immunoreactivity for 8-OHdG in nuclei of tumor cells was more frequent in cases positive for p53 and nuclear survivin, even though the difference was not statistically significant. However, when nuclear and cytoplasmic 8-OHdG staining were evaluated in combination, total 8-OHdG resulted significantly associated with $\mathrm{p} 53$ $(\mathrm{P}=0.026)$ and with nuclear or total (nuclear and cytoplasmic staining evaluated in combination) survivin immunoreactivity, with borderline significance $(\mathrm{P}=0.095)$. 
Table II. 8-OHdG expression in relation to $\mathrm{p} 53$, survivin, hOGG1 and G6PD.

\begin{tabular}{lccr}
\hline & \multicolumn{2}{c}{ Total 8-OHdG } & \\
\cline { 2 - 3 } & \multicolumn{2}{c}{ No. of cases } & \\
\cline { 2 - 3 } & Negative & Positive & P-value \\
\hline p53 & & & 0.026 \\
Negative & 8 & 21 & \\
Positive & 4 & 46 & \\
Nuclear survivin & & & \\
Negative & 7 & 20 & \\
Positive & 5 & 47 & 0.095 \\
Total hOGG1 & & & \\
$\quad$ Negative & 9 & 21 & $>0.05$ \\
Positive & 3 & 43 & \\
G6PD & & & \\
Negative & 10 & 49 & \\
Positive & 2 & 17 & \\
\hline
\end{tabular}

${ }^{\mathrm{a} F i s h e r ' s ~ e x a c t ~ t e s t . ~}$

There seemed to be no correlation between cytoplasmic survivin and p53 or $8-\mathrm{OHdG}(\mathrm{P}>0.05)$. A significant association was found between $\mathrm{p} 53$ and survivin expression, both when nuclear and total survivin was evaluated $(\mathrm{P}<0.0001)$.

hOGG1-positive tumor cells were more frequent in cases positive for 8-OHdG and when analyzed by Fisher's exact test, total hOGG1 correlated with total $8-\mathrm{OHdG}$ expression $(\mathrm{P}=0.009)$. Cases positive for total $8-\mathrm{OHdG}$ were often negative for G6PD, even though the difference was not significant $(\mathrm{P}>0.05)$, while the absence of total hOGG1 immunoreactivity was significantly associated with the negativity for G6PD $(\mathrm{P}=0.005)$. Total 8-OHdG expression in relation to $\mathrm{p} 53$, nuclear survivin, total hOGG1 and G6PD is presented in Table II. Despite the lack of statistical significance, there was a tendency that nuclear hOGG1-negative cells were positive for $\mathrm{p} 53$.

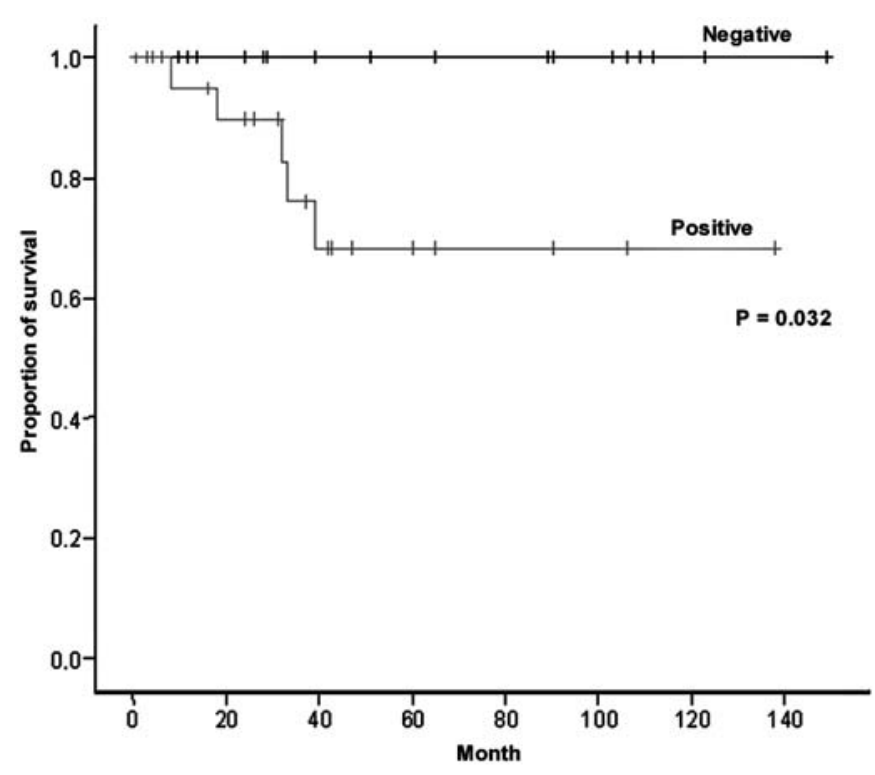

Figure 4. Kaplan-Meier survival function for overall survival among melanoma patients by different expression of nuclear $8-\mathrm{OHdG}$.

In survival analysis, Kaplan-Meier univariate analysis demonstrated that patients with tumors negative for nuclear $8-\mathrm{OHdG}$ had significantly longer survival time compared with those with nuclear 8-OHdG-positive tumors ( $\mathrm{P}=0.032$; Fig. 4). The Kaplan-Meier estimates of overall survival probabilities at 60 months were 1 for the patients with absence of nuclear 8-OHdG expression and 0.68 (95\% CI: 0.44-0.92) for those with nuclear 8-OHdG-positive tumors (Table III).

The multivariate analysis demonstrated that the predictive value of nuclear $8-\mathrm{OHdG}$ expression maintained the significance after adjusting the model by clinicopathological factors, such as tumor thickness $(\mathrm{P}=0.030)$, Clark level $(\mathrm{P}=0.053)$ and AJCC stage $(\mathrm{P}=0.039)$. On the contrary, cancerspecific survival of patients seemed not to be associated with hOGG1 or G6PD expression.

In correlation analysis, we did not observe a statistically significant association between 8-OHdG, hOGG1 and G6PD expression and clinicopathological factors, such as gender, age, tumor thickness, Clark level, stage and anatomic site $(\mathrm{P}>0.05)$.

Table III. Univariate analysis of 8-OHdG expression for 5-year survival in melanoma patients.

\begin{tabular}{|c|c|c|c|c|c|}
\hline Variable & No. of patients & No. of events & $\%$ 5-year survival & $\mathrm{SE}^{\mathrm{a}}(\%)$ & P-value ${ }^{b}$ \\
\hline Nuclear 8-OHdG & & & & & 0.032 \\
\hline Negative & 20 & 0 & 100 & - & \\
\hline Positive & 26 & 5 & 68 & 12 & \\
\hline Total 8-OHdG & & & & & 0.132 \\
\hline Negative & 9 & 0 & 100 & - & \\
\hline Positive & 37 & 5 & 74.8 & 10.1 & \\
\hline
\end{tabular}

a Standard error and ${ }^{\mathrm{b}}$ log-rank test. 


\section{Discussion}

UV radiation (UVR) is the only environmental carcinogen known to affect the risk of developing melanoma $(28,29)$. The biological effects of UVR span from DNA damage to cell signaling, to metabolism, to immune response (30). The 8-OHdG lesion, a sensitive marker of oxidative DNA damage, is suspected to be involved in the photocarcinogenic process initiated by sunlight (2).

In vitro studies have demonstrated that $8-\mathrm{OHdG}$ accumulates in cellular DNA and causes mispairing, suggesting that this oxidative modification is mutagenic and carcinogenic (31). Elevated levels of 8-OHdG have been linked to increased risk of breast, bladder, basal cell cancers (32-34) and have been regarded as an independent prognostic factor in different types of cancer $(9,14)$.

According with these studies, we found that positive immunoreactivity for $8-\mathrm{OHdG}$ in nuclei of melanoma cells is significantly associated with poor overall survival and might be useful as a predictor of clinical outcome in melanoma patients. The immunoreactivity for $8-\mathrm{OHdG}$ in the cytoplasm of tumor cells and epithelium was considered to reflect oxidative damage to mitochondrial DNA; however, it is clear that this widespread mitochondrial damage was unimportant with regard to melanoma progression.

Our results also showed that total 8-OHdG immunostaining is significantly associated with p53 expression, that is consistent with previous findings on tissues exposed to oxidative stress-inducing factors, that provide evidence of the concomitant presence of high expression of $8-\mathrm{OHdG}$ and overexpression of p53 (35). UV radiation, in addition to inducing oxidative DNA damage, detectable by an increase of $8-\mathrm{OHdG}$ expression in cells nuclei, can also cause mutations in genes such as p53 that, when inactivated through mutation and loss of heterozygosity, can lead to cell proliferation and genomic instability (36). Moreover, G:C to $\mathrm{T}$ :A transversions, induced by the presence of $8-\mathrm{OHdG}$ during DNA replication, has been found in the p53 gene in human skin cancers of sun-exposed areas and in UV-induced mouse skin cancers (37). Such mutations are believed to lead to an increased stability of this protein, allowing its more pronounced immunohistochemical detection. It is known that UV irradiation of mammalian cells leads to an increase in detectable p53 protein in the nucleus. Therefore, the study of both DNA damage induction and p53 status is a very informative way to evaluate the intensity of a given photogenotoxic stress (38).

Our results also showed a significant correlation between the expression of p53 and nuclear survivin, supporting previous findings that suggest p53 as a transcription inhibitor factor of survivin and the functional loss of wild-type p53, for UVinduced gene alterations, as the possible mechanism responsible for survivin overexpression in melanoma (39). The present study suggests that oxidative DNA damage, p53 functional loss, and survivin overexpression may all be involved in the process of melanoma pathogenesis.

One of the main DNA repair mechanisms involved in fixing UVR-mediated DNA damage is base excision repair (BER) and hOGG1 is the enzyme involved in the excision and removal of $8-\mathrm{OHdG}$ adducts. From our data, the immuno- histochemical expression of hOGG1 and G6PD, an other enzyme involved in protection against oxidative damage, did not show a significant correlation with survival in melanoma patients.

Immunopositivity for total hOGG1 in tumor cells was significantly associated with total $8-\mathrm{OHdG}$ expression, indicating that hOGG1 expression may be interpreted as a biomarker of exposure to oxidative DNA damage with induction of new enzyme synthesis, as suggested by previous studies, rather than a marker of inborn DNA repair capacity (10).

Cases positive for total $8-\mathrm{OHdG}$ were often negative for G6PD, even though the difference was not significant. The absence of total hOGG1 immunoreactivity was significantly associated with the negativity for G6PD. These results could indicate an imbalance in the independent repair mechanisms of hOGG1 and G6PD in the presence of oxidative stress in melanoma cells, even though further studies are required to clarify the function of these enzymes against oxidative damage. Despite the lack of statistical significance, there was a tendency that nuclear hOGG1-negative cells were positive for $\mathrm{p} 53$. This result is in agreement with previous findings indicating that loss of p53 function, consistent with its immunohistochemical overexpression, can lead to decreased hOGG1 expression (40). However, the precise mechanism by which p53 may regulate hOGG1 expression is still under investigation.

In conclusion, because of the importance to identify novel molecular prognostic indicators for melanoma patients, the present study suggests that patients with tumors positive for nuclear $8-\mathrm{OHdG}$ expression should be regarded as being at high risk of mortality and that nuclear $8-\mathrm{OHdG}$ could be useful as an early independent prognostic factor in patients with primary cutaneous melanoma, in association with the other prognostic markers currently in use. This could be regarded in the prevention of melanoma development by avoiding exposure to UV light, capable of inducing oxidative DNA modifications responsible for melanoma pathogenesis. On the other hand, the evaluation of $8-\mathrm{OHdG}$ in tumor cells might aid patient selection for adjuvant therapies and represent a valid target for treatment.

\section{Acknowledgements}

This study was supported by grants from the Ministero Istruzione Università Ricerca - MIUR, Ministero Affari Esteri - MAE and Fondazione Banco di Sardegna. Particular thanks are due to Mrs. Itala Mosso and Mr. Massimo Annis for their expert technical assistance.

\section{References}

1. Bickers DR and Athar M: Oxidative stress in the pathogenesis of skin disease. J Invest Dermatol 126: 2565-2575, 2006.

2. Marrot L and Meunier JR: Skin DNA photodamage and its biological consequences. J Am Acad Dermatol 58: S139-S148, 2008.

3. Sander CS, Hamm F, Elsner P and Thiele JJ: Oxidative stress in malignant melanoma and non-melanoma skin cancer. Br J Dermatol 148: 913-922, 2003.

4. Wei Q, Lee JE, Gershenwald JE, Ross MI, Mansfield PF, Strom SS, Wang LE, Guo Z, Qiao Y, Amos CI, Spitz MR and Duvic M: Repair of UV light-induced DNA damage and risk of cutaneous malignant melanoma. J Natl Cancer Inst 95: 308-315, 2003. 
5. Bruner SD, Norman DP and Verdine GL: Structural basis for recognition and repair of the endogenous mutagen 8-oxoguanine in DNA. Nature 403: 859-866, 2000.

6. Ichihashi M, Ueda M, Budiyanto A, Bito T, Oka M, Fukunaga M, Tsuru K and Horikawa T: UV-induced skin damage. Toxicology 189: 21-39, 2003

7. Cheng KC, Cahill DS, Kasai H, Nishimura S and Loeb LA: 8Hydroxyguanine, an abundant form of oxidative DNA damage, causes $\mathrm{G} \rightarrow \mathrm{T}$ and $\mathrm{A} \rightarrow \mathrm{C}$ substitutions. J Biol Chem 267: 166-172, 1992.

8. Hussain SP and Harris CC: Molecular epidemiology of human cancer: contribution of mutation spectra studies of tumor suppressor genes. Cancer Res 58: 4023-4037, 1998.

9. Shen J, Deininger P, Hunt JD and Zhao H: 8-Hydroxy-2'deoxyguanosine $(8-\mathrm{OH}-\mathrm{dG})$ as a potential survival biomarker in patients with nonsmall-cell lung cancer. Cancer 109: 574-580, 2007

10. Hatt L, Loft S, Risom L, Møller P, Sørensen M, RaaschouNielsen O, Overvad K, Tjønneland A and Vogel U: OGG1 expression and OGG1 Ser326Cys polymorphism and risk of lung cancer in a prospective study. Mutat Res 639: 45-54, 2008 .

11. Cheng ML, Ho HY, Wu YH and Chiu DT: Glucose-6-phosphate dehydrogenase-deficient cells show an increased propensity for oxidant-induced senescence. Free Radic Biol Med 36: 580-591, 2004.

12. Cooke MS, Evans MD, Dizdaroglu M and Lunec J: Oxidative DNA damage: mechanisms, mutation, and disease. FASEB J 17: 1195-1214, 2003.

13. Loft $\mathrm{S}$ and Poulsan HE: Cancer risk and oxidative DNA damage in man. J Mol Med 74: 297-312, 1996.

14. Miyake H, Hara I, Kamidono S and Eto H: Prognostic significance of oxidative DNA damage evaluated by 8 -hydroxy-2'-deoxyguanosine in patients undergoing radical nephrectomy for renal cell carcinoma. Urology 64: 1057-1061, 2004.

15. Räsänen JV, Sihvo EI, Ahotupa MO, Färkkilä MA and Salo JA: The expression of 8-hydroxydeoxyguanosine in oesophageal tissues and tumours. Eur J Surg Oncol 33: 1164-1168, 2007.

16. Cheng AJ, Chiu DT, See LC, Liao CT, Chen IH and Chang JT: Poor prognosis in nasopharyngeal cancer patients with low glucose-6-phosphate-dehydrogenase activity. Jpn J Cancer Res 92: 576-581, 2001

17. Paz-Elizur T, Krupsky M, Blumenstein S, Elinger D, Schechtman E and Livneh Z: DNA repair activity for oxidative damage and risk of lung cancer. J Natl Cancer Inst 95: 1312-1319, 2003.

18. Renzing J, Hansen S and Lane DP: Oxidative stress is involved in the UV activation of p53. J Cell Sci 109: 1105-1112, 1996.

19. Mirza A, McGuirk M and Hockenberry TN: Human survivin is negatively regulated by wild-type p53 and participate in p53dependent apoptotic pathway. Oncogene 21: 2613-2622, 2002.

20. Salvesen GS and Duckett CS: Apoptosis: IAP proteins: blocking the road to death's road. Nat Rev Mol Cell Biol 3: 401-410, 2002.

21. Adida C, Crotty PL, McGrath J, Berrebi D, Diebold J and Altieri DC: Developmentally regulated expression of the novel cancer anti-apoptosis gene survivin in human and mouse differentiation. Am J Pathol 152: 43-49, 1998.

22. Altieri DC: The case for survivin as a regulator of microtubule dynamics and cell-death decisions. Curr Opin Cell Biol 18: 609-615, 2006
23. Altieri DC: Validating survivin as a cancer therapeutic target. Nat Rev Cancer 3: 46-54, 2003.

24. Zaffaroni N, Pennati M and Daidone MG: Survivin as a target for new anticancer interventions. J Cell Mol Med 9: 360-372, 2005.

25. Torabian S and Kashani-Sabet M: Biomarkers for melanoma. Curr Opin Oncol 17: 167-171, 2005.

26. Clark WH Jr, Elder DE, Guerry D IV, Braitman LE, Trock BJ, Schultz D, Synnestvedt M and Halpern AC: Model predicting survival in stage I melanoma based on tumor progression. J Natl Cancer Inst 81: 1893-1904, 1989.

27. Greene FL, Page DL, Fleming ID, Fritz A, Balch CM, Haller DG and Morrow M (eds). In: American Joint Committee on Cancer Staging Manual. 6th edition, Springer, Philadelphia, 2002.

28. Moan J, Porojnicu AC and Dahlback A: Ultraviolet radiation and malignant melanoma. Adv Exp Med Biol 624: 104-116, 2008.

29. Zaidi MR, Day CP and Merlino G: From UVs to metastases: modeling melanoma initiation and progression in the mouse. $\mathrm{J}$ Invest Dermatol 128: 2381-2391, 2008.

30. Benjamin CL, Melnikova VO and Ananthaswamy HN: Models and mechanisms in malignant melanoma. Mol Carcinog 46: 671-678, 2007.

31. Seki S, Kitada T, Yamada T, Sakaguchi H, Nakatani K, Onoda N and Satake K: Immunohistochemical detection of 8-hydroxydeoxyguanosine, a marker of oxidative DNA damage, in human chronic cholecystitis. Histopathology 40: 531-535, 2002.

32. Kaczmarek P, Blaszczyk J, Fijalkowski P, Sierakowska-Fijalek A, Niemirowicz J, Kasprzak A and Baj Z: Assessment of 8-hydroxy2'-deoxyguanosine concentrations in bladder cancer patients treated with intravesical BCG instillation. Pol Merkur Lekarski 19: 526-528, 2005.

33. Malins DC, Anderson KM, Jaruga P, Ramsey CR, Gilman NK, Green VM, Rostad SW, Emerman JT and Dizdaroglu M: Oxidative changes in the DNA of stroma and epithelium from the female breast: potential implications for breast cancer. Cell Cycle 5: 1629-1632, 2006.

34. Nishigori C, Arima Y, Matsumura Y, Matsui M and Miyachi Y: Impaired removal of 8-hydroxydeoxyguanosine induced by UVB radiation in naevoid basal cell carcinoma syndrome cells. Br J Dermatol 153: 52-56, 2005.

35. Perra MT, Maxia C, Corbu A, Minerba L, Demurtas $P$, Colombari R, Murtas D, Bravo S, Piras F and Sirigu P: Oxidative stress in pterygium: relationship between $\mathrm{p} 53$ and 8-hydroxydeoxyguanosine. Mol Vis 12: 1136-1142, 2006.

36. Reisman D, McFadden JW and Lu G: Loss of heterozygosity and p53 expression in Pterygium. Cancer Lett 206: 77-83, 2004

37. Nishigori C: Cellular aspects of photocarcinogenesis. Photochem Photobiol Sci 5: 208-214, 2006.

38. Marrot L, Belaidi JP and Meunier JR: Importance of UVA photoprotection as shown by genotoxic related endpoints: DNA damage and p53 status. Mutat Res 571: 175-184, 2005.

39. Piras F, Perra MT, Murtas D, Minerba L, Floris C, Maxia C, Demurtas P, Ugalde J, Ribatti D and Sirigu P: Combinations of apoptosis and cell-cycle control biomarkers predict the outcome of human melanoma. Oncol Rep 20: 271-277, 2008.

40. Chatterjee A, Mambo E, Osada M, Upadhyay S and Sidransky D: The effect of p53-RNAi and p53 knockout on human 8oxoguanine DNA glycosylase (hOgg1) activity. FASEB J 20: $112-114,2006$. 